Author Bio: Kornelia Tancheva, PhD is the former Instruction Coordinator and current Public Services Librarian at Albert R. Mann Library, Cornell University. Camille Andrews is the current Instruction Coordinator at Albert R. Mann Library, Cornell University. Gail Steinhart is the Environmental Sciences and GIS Librarian at Albert R. Mann Library, Cornell University.

\title{
Library Instruction Assessment in Academic Libraries
}

\author{
Kornelia Tancheva, Ph.D., Camille Andrews, Gail Steinhart
}

\begin{abstract}
Determining the best methods of assessment for a library instruction program in a large research university can be a challenging task. Albert R. Mann Library at Cornell University Library has pilot tested three methods of formative and summative assessment for its library instruction programattitudinal, outcomes-based, and gap-measure - and determined not only key areas of improvement for the program, but also the benefits and drawbacks of each method of assessment. Attitudinal assessment has guided program improvement in areas of marketing and user satisfaction but does not provide the measurement of learning that outcomes-based assessment covers. The latter can be difficult to achieve in single-session, short-term instruction, while gap-measure assessment can provide a more nuanced view of both patron and instructor attitudes toward learning outcomes, if not actual data on achievement on the objectives themselves. The authors have determined that a combination of these three different types of assessment can address the shortcomings of a single method alone and provide a better measure of the program as a whole.
\end{abstract}

Keywords: information literacy, assessment, evaluation, college and university libraries

Assessment of library instruction is a growing topic of concern for library instructors as evidenced by the 246 articles found in Library Literature on evaluation of bibliographic instruction (more in the last two years than in the previous six combined). A number of assessment models are available for library instruction; however, with the wide range of methods and their varying utility depending on the format and type of instruction being assessed, choosing and implementing models can be difficult. It is our contention that to present a well-rounded picture of an instruction program, more than one method of assessment is necessary. Over the last two years, the staff at Albert R. Mann Library at Cornell University Library (CUL) has pilot-tested a three-pronged approach to assessment. The first assessment was an evaluation of the entire CUL instruction program using focus groups and a Web-based statistical survey; the second outcomes-based assessment, focused on a single courserelated instruction session at Mann Library, consisted of a pre-test survey and examination of the results of a post-instruction tutorial assignment; and a third assessment featured a gap-measure analysis of instructors' and students' perceptions of the importance of the learning objectives in Mann Library's open workshop series. Below we present our findings and their effect on our instruction program, address the benefits and limitations of these various types of assessment, and show that a multi-method model of assessment, both formative and summative, is key to a clear picture of the various aspects of our instruction program.

\section{ASSESSMENT OF LIBRARY INSTRUCTION}

Evaluation of library instruction has its origin in a larger movement of education reform that began in 
the 1980's (Bober, Poulin \& Vileno, 1995). The motivations for assessing instruction are several; these include demonstrating institutional accountability for student learning, defining and measuring information competencies, developing indicators of library performance, meeting accreditation requirements, and improving instruction (Knight, 2002). Other factors motivating assessment include the rise of strategic planning to align library goals with those of their parent institutions, and the development of the concept of information literacy (Meulemans, 2002; Smith, 2000). The impact of the information literacy concept on accreditation standards and metrics is evident from the various reports issued by accrediting bodies and professional organizations. These include a 1990 report of the American Library Association's Presidential Committee on Information Literacy, the 1994 adoption of information literacy standards and indicators by the Middle States Association of Schools and Colleges, and the creation of information literacy competency standards by the Association of College and Research Libraries in 2000 (Meulemans, 2002).

In considering the nature and purpose of assessment, it's worth considering the meaning of the term. The terms evaluation and assessment are sometimes used interchangeably, but Rabine and Cardwell (2000) make an important distinction. They reserve "evaluation" for the appraisal of services, while asserting that "assessment" is focused on users. This difference is akin to that between summative and formative evaluation. Formative evaluation is typically used to guide program improvement, while summative evaluation is used to determine whether program objectives are being met (Rossi \& Freeman, 1993). If one is concerned with instructor performance, relevance of course materials and exercises, facilities, and other similar factors, then a formative evaluation is the appropriate approach. If the focus is instead on learning outcomes, or what recipients of library instruction actually gain from the experience, a summative assessment is in order. In this paper, we will use the terms assessment and evaluation interchangeably, but will maintain the distinction between summative and formative approaches. Upon reviewing instruction and assessment goals, one should be able to determine which type of assessment is in order.

Published assessments of both types are abundant, and often the approaches are combined. With the rise of the information literacy movement and its impact on bibliographic instruction, however, there has been a shift in emphasis from inputs and outputs as measures of institutional effectiveness to users and outcomes (Hernon, 2002; Thompson, 2002). Such summative evaluations have been usefully applied to multiple-session or credit-bearing instruction, and to course-integrated instruction when faculty are willing. The approach is more accessible for multiple-session instruction due to the nature of the methods that are commonly employed. These include pre- and post-tests, research journals, bibliographies, portfolios, and other course assignments. This approach gives some idea of the impact instruction has on student performance. Students are given an opportunity to put to use the skills obtained from library instruction, and the products can be used to evaluate the efficacy of the instruction. One drawback to this approach (and others) is the lack of statistical controls. Including a control group in the study design means denying library instruction to a group, something that is generally considered unethical (Bober et al., 1995). Frick (1990) argues that lack of statistical rigor is not necessarily a fatal flaw of qualitative evaluations, if the intent is to evaluate a program's impact on student learning, and if one wants to avoid imposing pre-conceived notions on the participants.

Single-session or "one-shot" instruction presents some special problems when it comes to assessment. Formative evaluations are most commonly employed, and these can be useful in guiding program improvements. The American Library Association's manual (Shonrock, 1996) for evaluating library instruction is heavily weighted towards formative evaluation; twelve of the 
fourteen sections that present model questions for evaluation instruments are devoted to issues related to instructional programs rather than learning outcomes. Perhaps Ragains' (1997) report on the results of a national survey of evaluation practices should come as no surprise; nearly 75\% of respondents report the use of "reaction data" (satisfaction surveys), while less than half that report testing student knowledge. This reliance primarily on reaction or attitudinal data has been criticized for failing to measure what students actually learn (Colborn \& Cordell, 1999): “At most, it provides information about how the student perceives the librarian's presentation and how he or she feels about the library and/or librarian” (p. 125). In addition, when asked to evaluate their own skills, students may overestimate their competence when they are unfamiliar with the material being taught (Bober et. al., 1995; Knight, 2002). This emphasis on formative evaluation may have its roots in traditional methods of evaluating library services, and libraries have a long history using quantitative measurements for evaluation: circulation and holdings statistics, number of reference questions answered, and numbers of students participating in bibliographic instruction, to name a few examples (Rabine \& Cardwell, 2000; Iannuzzi 1999).

Despite the preponderance of published formative evaluations, some attempts have been made to take a summative approach to single-session instruction. These are by necessity quite a bit scaled back relative to evaluations done for multiple-session instruction, but something can be gained from these efforts nonetheless. In particular, course-related instruction offers more opportunities for outcomes-based evaluation, because tests or surveys can be administered after students have had a chance to use newly acquired skills, and related assignments or bibliographies may be reviewed. For standalone instruction, Barclay (1993) provides some encouragement for busy instruction librarians who are contemplating an assessment by reminding readers that some evaluation is probably better than no evaluation at all. In this case, testing, along with surveying, are often the only practical options for assessment. Testing has the potential to determine what students know (as opposed to what they think they know), as long as the test is a well-designed one. Tests with open-ended answers are generally considered to offer more reliable information than constructed answer questions (Roselle 1997), but these can be more difficult to score systematically. Barclay (1993) suggests crafting an ideal response for each open-ended question to facilitate scoring.

Stewart (1999) and Pausch and Popp (1997) provide some of the more useful and simple techniques for use in classroom assessment, derived from assessment practices in higher education. One method is a "minute paper," where students are asked to answer questions such as: "What was the most important thing you learned in this class?" or "What important question remains unanswered?" Others are the "one sentence summary" of what students learned, and the "muddiest point" or least clear portion of the instruction session. Rabine and Cardwell (2000) present a four-part approach consisting of student, faculty, peer, and self-assessments. The student portion of the assessment is a constructed answer post-test designed to test what students have learned. Barclay (1993) proposes using a couple of open-ended short answer test questions for the same purpose. Fenske and Roselle (1998) applied multiple assessment methods to single-session course-related instruction. Students were asked to complete two surveys, one immediately following the instruction session, and one following completion of an assignment. Teaching assistant surveys and peer evaluations were also used. The student surveys consisted primarily of constructed-answer questions, but did include one or two open-ended questions, thus combining formative and summative approaches.

The literature on assessment suggests that difficult as it may seem, a summative approach is appropriate for evaluating single-session library instruction if one is concerned with learning outcomes. However, even if one is focused on outcomes, Barclay's (1993) admonition is worth 
keeping in mind: "no evaluation should be undertaken with only these goals in mind. Unless evaluation will somehow improve the thing being evaluated, it is not worth doing” (p. 199).

\section{ATTITUDINAL ASSESSMENT}

The Cornell University Library (CUL) have had a well-developed library instruction program for undergraduate students, graduate students, faculty, alumni, staff, as well as various specialized audiences, since the 1970s. The program includes tours, orientation sessions, course-integrated research sessions, open workshops, information literacy credit courses, and research methods courses. Librarians also create library assignments and Web-based class and subject guides and offer individual and group consultations to students working on projects and research papers.

Until the early 2000s, evaluation of the Cornell community's participation in and satisfaction with these sessions was done on an ad hoc-basis with various evaluation instruments used in different sessions and by different instructors. In 2001, the CUL Instruction Working Group (IWG), a campuswide interest group of reference and instruction librarians, won a CUL internal grant to conduct a comprehensive investigation of the library instruction experience of students, faculty and staff. The assessment took two forms, focus groups and a statistical survey. The complete results of the assessment are available in an online report at http://techreports.library.cornell.edu:8081/Dienst/UI/ 1.0/Display/cul.lib/2005-4. Below we present only some of the most salient conclusions.

The focus groups with faculty, students and staff, conducted by the South Central Regional Library Council (SCRLC) in October of 2002, revealed that an overwhelming majority of the 54 participants in the 6 focus groups were not only familiar with the instruction offerings of CUL but were also favorably impressed with them. However, they did not perceive the libraries as having a systematic instruction program; rather, they talked of separate sessions that they happened to take. Not surprisingly, the most effective way of advertising library instruction to students was through their instructors and course syllabi or course Web sites; while faculty still preferred paper notices in their mailboxes. All participants expected library instruction to be related to an immediate need: an assignment, a research paper, an upcoming presentation, etc. The most effective type of library instruction was perceived to be instruction tailored to a course or an assignment, scheduled close to the actual due date, preferably in a hands-on computer lab, accompanied by customized paper or online handouts, and reinforced in one-on-one sessions at the reference desk or in consultation settings. Interestingly, participants in the focus group were not particularly enthusiastic about the prospect of online research tutorials. They considered in-person sessions most effective and clearly preferred them; they pointed out that online tutorials had a number of drawbacks: lack of instant live feedback, confusing interfaces, and inordinate length, among other problems. Students dismissed the idea of required library instruction credit courses and instead emphasized the need to offer more workshops on citation management, data extraction, and customized help with assignments and research.

After the completion of the focus groups and the preliminary analysis of the findings, the IWG designed and distributed a survey questionnaire in order to measure the statistical validity and significance of the opinions expressed by the focus group participants. Following a pilot version distributed to 40 participants in December 2002 in order to clarify terminology and disambiguate the questions, the IWG created a Web-based questionnaire the following January, which was distributed to a simple random sample of 1,000 undergraduate students, 1,000 graduate students, and 1,236 
faculty members. The total response rate was $22.40 \%: 21.1 \%$ for graduate students, 12.7 for faculty and 35.7 for undergraduate students.

The survey addressed several major questions: the level of participation of the campus community in the CUL instruction offerings, the users' level of satisfaction with these, the promotion materials most likely to reach faculty and students, the level of usage of and satisfaction with library instruction materials (subject guides, class bibliographies, tutorials, and help pages), as well as the faculty's levels of awareness of and satisfaction with course-integrated library instruction. Demographic questions were included in the survey in order to explore possible significant differences among colleges and/or departments. Ultimately, the analysis revealed no significant differences among colleges, and the department information was too disparate to allow for any statistical validity. Hence the analysis presents aggregate data.

Although ARL identifies one-on-one interactions at the desk as reference rather than instruction, the focus group participants had indicated that patrons considered drop-in sessions at the reference desk and consultations a form of library instruction. They remarked particularly on the fact that they often came to the desk to find out how to do their research as opposed to receiving an answer to a specific factual question. It seemed more important to them to understand the process and be able to apply the techniques learned independently in their future research. In other words, often they viewed reference interactions as teaching moments. Hence, our final questionnaire included them along with tours, workshops, and course-integrated sessions. As Figure No.1 indicates, the most frequently attended library instruction sessions varied by patron category. While for undergraduate students, these clearly were the course integrated sessions, with $54.2 \%$ of the undergraduate respondents reporting having attended at least one; faculty were a lot more likely to use the services of the reference desk than both graduate or undergraduate students. Close to $55 \%$ of the faculty respondents indicated that they had used the services of the reference desk. The most popular form of library instruction among graduate students was the orientation tour, with $39.2 \%$ of respondents indicating having attended one.

[Insert Figure 1: Instruction Session Attendance (Percent of Responding).]

Patron satisfaction with the library instruction sessions they had attended was uniformly high. Without exception, all patron categories rated all types of instruction either helpful or very helpful in over $90 \%$ of the cases, and in some instances, in $100 \%$ of the cases. For example, $100 \%$ of faculty attending open workshops found them "helpful" or "very helpful" and $100 \%$ of graduate students who attended a consultation rated it "helpful" or "very helpful." While the number of users rating a session as "not very helpful" was very low, there was a pattern in all patron groups: the highest relative rate of dissatisfaction was exhibited with tours in the total population, the faculty category, and both student categories. Clearly, the most critical patron group is that of the undergraduate students, where the percentages of users choosing "not very helpful" are relatively highest. Figures 24 present patron satisfaction levels by patron category and instructional offering.

[Insert Figure 2: Total Faculty Satisfaction]

[Insert Figure 3: Total Graduate Student Satisfaction]

[Insert Figure 4: Total Undergraduate Student Satisfaction]

The most popular means of advertising library instruction again differed by patron category. For faculty, the most popular form was e-mail (26\%), followed by colleagues (23\%), fliers/posters 
(22\%), and only rarely Web pages (9\% of instances). In their turn, faculty serve as the most important source of information about library instruction both for undergraduate students (48\% of instances) and graduate students (24\% of instances). The qualitative analysis of the free-text comments also revealed that faculty and graduate students are much more likely to actively seek out librarians' help, while undergraduate students are more likely to "stumble across" information about library instruction, which underscored the importance of effective, eye-catching advertising in the building, as some of the participants in the focus groups had suggested.

One of the findings that was somewhat surprising was the comparatively low usage of library instruction materials: subject guides, class bibliographies, tutorials, and help pages. The cumulative percentages for each category of patrons who reported never having used any library materials were $51 \%$ for faculty, $58.5 \%$ for graduate students, and $57.5 \%$ for undergraduate students. Respondents appeared most familiar with help pages, followed by subject guides, class bibliographies, and tutorials. Figure 5 presents the findings by type of library material and patron category.

[Insert Figure 5: Library Instructional Materials Usage (Percent of Responding)]

Users who had used any of those materials at least once were asked to rate their usefulness. No format received a $100 \%$ user satisfaction level of "helpful" or "very helpful," in contrast to the instruction sessions. Figure 6 presents the total patron satisfaction with instructional materials by type of material and patron category.

[Insert Figure 6: Total Patron Satisfaction with Instructional Materials]

Finally, the survey attempted to measure the instructors' satisfaction level with the course-integrated library instruction sessions that they had arranged for their classes. Since there are a significant number of graduate students who teach in the Freshman Writing Seminar series at Cornell, the question was included both on the faculty and the graduate student questionnaires. Of the graduate students and faculty who had arranged a class-integrated session for their courses, all found it either "helpful or "very helpful," with faculty reporting a somewhat higher level of satisfaction (70\% thought the sessions was "very helpful," while only 52\% of graduate students reported it was "very helpful), as Figure 7 indicates.

[Insert Figure 7: Instructor Perception of the Usefulness of Course-Related sessions.]

What the focus groups and the survey indicated was that both the levels of participation in and satisfaction with the library instruction at Cornell were very high among all three patron categories. The comparatively low familiarity with and usage of the library instruction materials in the survey seemed to parallel the focus groups' greater interest in live sessions as opposed to tutorials. The focus group findings suggested that library instructors needed to increase the visibility of the instruction offerings and enhance the patrons' perception of a complete and unified library instruction program instead of unconnected pieces. Finally, the survey also suggested better and more targeted approaches for effective marketing of all of our instructional offerings to the various patron groups (e.g., more targeted e-mail and flyers and focus on marketing of consultations and course-related instruction for instructors, better in-building advertising and focus on increasing user satisfaction for undergraduates).

As a broad attitudinal assessment of satisfaction levels, focus groups and statistical surveys provided 
useful data for future planning and marketing efforts. However, high levels of satisfaction are only an indirect measure of actual learning. In order to measure the effectiveness of library instruction beyond increasing the general positive perception of the library as a whole by the campus community, an outcomes-based assessment instrument was required.

\section{OUTCOMES-BASED ASSESSMENT}

In an effort to pilot test an outcomes based-assessment at Albert R. Mann Library, in September 2005 Kornelia Tancheva, the Instruction Coordinator at the time, and Camille Andrews, then a Public Services Librarian, administered a pre-test survey (Appendix 1) to 79 students in the AEM 101: Introduction to Applied Economics and Management class. This college transition course is limited to freshmen and exposes them to the field of applied economics and management as well as introduces them to skills and services they will need to be successful in college, including an understanding of library resources. Typically, the class is split into several sections, each coming in for library sessions taught by Mann Library instructors over the course of two days. As part of their library session and assignment for the class, students must also begin a library-designed tutorial which they can complete in the week or two following the instruction session. This tutorial assignment served as a post-instruction assessment tool (Appendix 2).

For many of these students, the session that Mann Library holds is their first introduction to the resources of the Cornell University Library and may be their first exposure to library resources in general. Our main objectives were to test students' knowledge of citation formatting in order to gauge their familiarity with a basic library concept and, moving beyond simple identification, to ask them how to find the full-text article in order to check their understanding of how to retrieve information in the library (both virtually and physically). Before the session began, we gave students a few minutes to fill in a worksheet that asked them to deconstruct a citation and identify its parts by filling in the blanks and to explain how they would find the article in an open-ended answer format as recommended by Roselle (1997).

While all of the students were able to correctly identify the author of the article and the year the article was published and $87 \%$ of the students correctly identified the page numbers, only $63 \%$ of the students were able to correctly identify the article title and $61 \%$ percent the journal title. The greatest amount of confusion occurred with the volume and issues numbers, where only $37 \%$ of students were able to correctly identify the volume number and 35\% the issue number. Figure 8 shows the results of the survey.

\section{[Insert Figure 8 Pre-Test Survey: Citation Exercise]}

Though these results are necessarily a limited sample, we conjecture that unfamiliarity with the conventions of citation formatting (e.g. italicization for the journal title and parentheses for issue numbers) or the lack of identifying features for parts of the citation may have confused some students. The uneven results of the pre-test indicate a clear need for the type of library instruction that we are providing.

This pilot survey also highlighted the necessity for additional attention to survey design and administration in the future. In some cases, students may not have paid attention to the parts of the citation we were asking for, as evidenced by the numerous deletions on the sheets when students 
looked more closely at the instructions. In addition, since we gave the worksheets out as students entered the class and collected them within the first five minutes, many students who entered late had a limited amount of time to complete the worksheet; indeed, a few students handed in their worksheets after the session was done, which may have skewed our results very slightly. Also, since it was clearly a non-graded exercise, students may have simply marked down the first answers that came to mind. Giving a set time limit and also making the worksheet part of their overall graded assignment might be ways to improve attention to results in the future.

For the open-ended question, "How would you find the article above?" the range of answers provided more insight into students' understanding of library research. Seventy-six students answered the free-text question out of the seventy-nine surveyed, with some students providing more than one answer; therefore, the results total more than $100 \%$.

Overall, students' conception of where to begin their search for the full-text article was very limited (see Figure 9).

\section{[Insert Figure 9: Pre-Test Survey: Location of Full-Text Article]}

$24 \%$ of the students did not specify a starting place for their search, but only what they would search for, indicating a lack of awareness that the site of the search would often determine its success. $17 \%$ mentioned searching the "library Web site" in some fashion, marking a trend we had noticed anecdotally. Many students do not seem to distinguish between the Library Gateway (CUL's Web portal to resources and services) and its components (the library catalog and the individual databases contained within it). With students who are increasingly used to searching the Web, where they assume that a search in a single search box will cover everything available (whether or not this is true), the idea that searching in different interfaces will produce different results may not be apparent. A smaller percentage of students than we would have predicted (16\%) mentioned using the Internet to find the article; half of those specifically mentioned Google. Only 8\% would ask a librarian (one even said a "friendly librarian," perhaps indicating a touch of library anxiety and the power a friendly face can have in determining whether students approach us).

For those who were aware of the distinctions between the Library Gateway and the resources found within it, thirteen students (or 17\%) indicated that they would search in a database (still often unspecified or vague- "Mann Library database" or "library database"-though some suggested specific databases such as Lexis-Nexis, JSTOR, and, in the case of one student who mistook the database provider for the database name, Ebscohost). Only four out of those thirteen were aware that it was possible to search by article title or author within the database; we believe this might be the case because most students thought you could search by article title or author anywhere, as indicated by the results on search strategy that follow. 11\% mentioned the library catalog specifically (though at least three students were under the impression that you could search for the article's author or title directly through the catalog and not a specific database). $4 \%$ mentioned using the library's e-journals search interface (though only one clearly indicated they understood that you can only search for journal titles not article titles through our e-journals service) and one mentioned our federated search, Find Articles.

At least $8 \%$ realized that the article might be available in print in the stacks in some manner (sometimes calling the print volumes the "archives," confusing them with the reference (or "encyclopedia”) section, or indicating they were searchable by author as well as journal but not 
mentioning their physical location). The awareness of print as an existing resource (however vague) is heartening, even if only one student indicated they understood clearly where the print volumes are and how to access them by specifically mentioning finding the call number and the journal's location in the stacks.

As for search strategies, the results were consistent with our findings that students believe that searching for any part of the citation anywhere will achieve successful results. Many students omitted any information on search strategies, but for the $46 \%$ of respondents who answered, $54 \%$ of these students simply mentioned searching for the article title and/or author without any indication that this approach would only work within a database rather than the Library catalog or in any search box on the "library Web site.". Another 9\% correctly indicated where to search. 29\% grasped the fact that they could look for the journal title, but only half of those went on to locate the correct volume and issue (or, once within the correct journal, search for the article title or author). $11 \%$ only said they would find the article "easily," using "references," by finding the author's name and matching it with the magazine and page numbers, or by expecting that the library Web site would give them directions on how to find full-text after searching for the author's last name. One student took the page numbers as a section number and suggested looking up the author's name there. Others decided vagueness was the better part of valor and suggested looking for "all of the citation" or "keywords pertaining to the info above," "plug[ging] in one piece of the info listed above," or "sort[ing] out the article that has the exact info listed above.” One student honestly admitted they had "no idea" how to find the article.

The results of both the fill-in-the-blank citation exercise as well as the open-ended question on how to find full-text show that, before the library session, students' mental models of how to read a citation and then find the full-text article were very unclear. During the library sessions, the instructors taught how to search the library catalog to find the journal and then locate the specific volume, issue and page numbers (either in print using the call number or in electronic format) and how to search a database for the article title, author or keywords,. The students began their library tutorial in class under the supervision of the librarians and were asked to complete it on their own time. The final assignment was collected and graded by their TAs, who provided a sample of 27 of the 79 final assignments to the librarians for use in this assessment.

The results for the post-instruction tutorial were much more encouraging.

\section{[Insert Figure 10: Post-Instruction Tutorial: Citation Exercise]}

After instruction, $96 \%$ of the students were able to correctly identify the article title, author, journal title, volume, issue and page numbers. $89 \%$ of the students indicated that the full-text article was available after the instruction session, which is much more encouraging than the free-text responses to the pre-test survey would have lead us to believe. Of those, $96 \%$ of those recognized that it was available in print (though only $81 \%$ identified the call number correctly) and $93 \%$ located the electronic version. However, when asked to find and print the first page of the article, only $70 \%$ of the students were able to comply. Some students pled technical difficulties in retrieving the article; however this does not completely explain the discrepancy between students who were aware the article existed in full-text in electronic format and those who were actually able to access it. This indicates that there was still some confusion on the part of students on how to retrieve the full-text (or a failure to read the final part of the question). Additionally, in the post-instruction citation exercise, only $52 \%$ of the students correctly identified the year of the article. However, we believe 
this was largely due to misreading on the part of the students rather than ignorance of the actual date (except in a few cases). In the tutorial, students were asked to identify the volume, issue, year and inclusive page numbers in one question. However, many students simply cut and pasted the citation information from the database (which gave the year in a different location). We believe that students who failed to read the question carefully or to look at the citation they pasted may have missed the year.

Overall, the results of the post-test instruction show an increased ability to identify the parts of a citation and retrieve the full-text article by locating the journal title through the catalog and identifying both the print and electronic copies. However, since the students could complete the tutorial during the session, in addition to the two-week period just after the class, it is difficult to ascertain whether the students' improved responses are the result of attention during the session or short-term recall. To prove that longer-term learning objectives were met, we would need to administer a similar post-instruction tutorial several weeks or months later. Additionally, without further assessment, it is difficult to ascertain the effects on students' overall conceptions of information organization (e.g. their ability to distinguish between Web searching and searching in library resources) or the applicability of instruction to other assignments and projects the student will be required to complete, both in and outside of class.

\section{GAP-MEASURE ASSESSMENT}

As our results show, outcomes-based assessment provides tangible measures for the effectiveness of library instruction. However, as we have noted, short-tem outcomes-based assessment may be biased on a number of levels (e.g. measuring students' immediate recall and lack of demonstrated connection to lifelong learning). While a recent study by Wang (2006) found that there were statistically significant differences in citation use and grades between students who took a library credit course and students who did not and that the students' acquisition of research and citations skills were directly attributable to the library credit course, assessing the learning effectiveness of a one-time library instruction session for student performance is an almost impossible task considering the number of variables and the possible problematic nature of designating a control group that would not receive instruction.

In order to provide yet another facet of the assessment of the effectiveness of library instruction, a third type of assessment, gap-measure assessment, can be included along with attitudinal and outcomes-based assessment. It attempts to measure the gap between the library instructor's perception of what the most important points in a session are going to be (anticipated salience), what the patrons' perception of the actual most important content in a session is (actual salience), and the instructor's post-session perception of the actual most important content (post-session salience).

To measure this gap, Kornelia Tancheva devised a Web-based survey to be distributed to patrons participating in the open workshops series in the fall of 2004, and conducted pre- and post-session interviews with the instructors. The evaluation was intended to measure the future feasibility of combining summative and formative approaches in the assessment of one-time library instruction sessions. The instrument (Appendix 3) asked the participants to state the most helpful things they learned in their respective workshops and things that they wanted to learn but didn't get a chance to. The total number of respondents was 126; and the number of instructors interviewed was 8 . 
The comparison between what patrons considered most helpful and what instructors considered the most important things before they taught the session revealed a gap between instructors' and patrons' perceptions. While the gap was insignificant in the introductory sessions (e.g. introductory EndNote, introductory Photoshop), in the advanced sessions on the same topics, over $15 \%$ of the three most important things mentioned by instructors were not mentioned by patrons among the things that they found most helpful. Interestingly, the post-session interviews with instructors in the advanced sessions revealed that the instructors' expectations had been "too advanced" and once in the classroom, they had had to cover things that they consider "introductory" and would normally include in basic sessions. This gap is an indication that measuring learning in "one-minute" papers might be problematic because of the patrons' differing levels of prior expertise on the subject. The question about having previously attended a library instruction session did not yield statistically significant results since equal numbers of patrons attending advanced sessions reported not having attending a previous instruction session and having attended the introductory session on the subject. A qualification should be made here, since the question was worded in a general manner that would address all sessions and did not specifically ask attendees at advanced sessions whether they had taken the introductory ones.

Many patrons attending multi-level sessions appeared to have misjudged their knowledge and expertise, a conclusion that was also supported by the analysis of the question about things that patrons expected to learn but did not. In over 95\% of the cases, in the post-session interviews, the instructors who were shown the patrons' responses, considered them either "too advanced" for an introductory workshop or "too introductory" for an advanced workshop.

In workshops that did not offer introductory and advanced levels, e.g. Library Research, Bioinformatics, Statistical Data Sources, Web Search Engines, Powerpoint), the salience gap between patrons' perceptions and instructors' pre-session perceptions appeared smaller than in the instances when both an introductory and advanced sessions were offered. Only $4.5 \%$ percent of the things that the instructors considered most important were not mentioned by patrons, a fact which seems a good indication of relatively well targeted workshop content. One finding that was interesting included the fact that people attending more specialized sessions (Bioinformatics, Biosis, PowerPoint) rated what was most helpful to them in terms similar to what the instructors considered most important in their pre-session interviews more often than those attending more general sessions (Library Research, Web Search Engines). The analysis of the prior experience of the patrons revealed that people attending library research sessions are generally less likely to have attended any previous library instruction and can thus be considered less experienced. It is possible, however, that the general nature of the subject matter also allowed for a greater gap between the instructors' and the attendees' perception of what is important.

Similarly, the attendees at the library research session were most likely to answer in the negative to the question of whether they did not get to learn something that they had wanted. In many cases, their answers were along the lines of "No, it was all very thorough," or "It is all new to me, I had no expectations."

The gap measure assessment of the workshop series proved useful in several respects. It provided instructors with direct feedback on the content of what they are teaching (or failing to teach), while assessing their effectiveness in general terms that may heavily be influenced by personal likes and/or dislikes, learning styles, etc. Further, it provided the Instruction Coordinator with an aggregate picture of the relevance of the workshop series content. As a direct measure of learning outcomes, its 
importance appears to be lower than that of outcomes-based assessment instruments.

\section{CONCLUSION}

Using three different types of assessment has provided a well-rounded picture of the instruction program at Mann Library and has pointed to some specific areas of improvement. The attitudinal assessment, though deficient in measuring actual learning outcomes, has been useful in pinpointing user satisfaction with the overall instruction program, which is generally high. From the results we have concluded that our marketing efforts for the program should be more integrated and targeted for particular groups and that our focus on course-integrated instruction and library workshops over printed and online library instructional guides has been generally successful. It has also suggested further areas of research into ways of improving instructional guides. The outcomes-based assessment of a course-integrated session has provided a clearer picture of the knowledge and skills of at least one sample group of freshmen and has indicated that more attention should be given to helping students understand where they are searching and what search strategy will provide the best results depending on the interface used. Follow-up assessments several weeks or months after the initial assignment and examination of the papers and projects produced by the students would also provide more reliable data on actual learning rather than short-term recall. Finally, the gap-measure assessment has provided additional detail not only on user satisfaction with our workshop program but also insight into the difference between instructors and students' perceptions of the importance of workshop content, which will allow us to better tailor our advanced workshops.

The pilot testing of these various forms of assessment has provided the instructors with a toolbox of assessment techniques that can be applied to other instructional situations or used to illuminate the results of previous assessments. For example, a gap-measure assessment of the tours and all forms of undergraduate instruction could help understand the causes of the higher levels of user dissatisfaction discovered during the attitudinal assessment of the whole instruction program. A combination of outcomes-based and gap-measure assessments for course-related instruction could provide data on instructors' and students' learning objectives, the differences between them and how well the instructors’ learning objectives are actually being met.

In addition, these assessments have provided us with data that are useful in advocating for the need for more attention to information literacy on a university-wide level. Recognizing the need for concentrated attention to this issue, Cornell University Library recently implemented a library-wide committee on information fluency (the term that Cornell prefers), and the results of these assessments have been used in the team's reports to and meetings with library administrators. In the future, we envision communicating the results to the University administration in order to emphasize the role of the library as a teaching institution and its integral participation in the mission of the research university.

We will continue to test a number of approaches to assessment, alone and in combination, as each one presents its own benefits and drawbacks. Though at times gaining a total picture of our instruction program may feel like the three blind men each touching a different part of the elephant, only through this kind of multi-method inquiry will we gain an accurate picture of our total effectiveness. 


\section{BIBLIOGRAPHY}

Barclay, D. (1993) Evaluating library instruction: doing the best you can with what you have. RQ 33(2), $195-202$.

Bober, C., Poulin, S., \& Vileno, L. (1995) Evaluating library instruction in academic libraries: a critical review of the literature, 1980-1993. The Reference Librarian 51-52, 53-71.

Colborn, N.W. \& Cordell, R.M. (1998) Moving from subjective to objective assessments of your instruction program. Reference Services Review 26(3-4), 125-37.

Cornell University Library Information Fluency Team. (n.d.) Retrieved April 25, 2006, from http://www.library.cornell.edu/staffweb/PriorityObjectives/3/

Frick, E. (1990) Qualitative evaluation of user education programs: the best choice? Research Strategies 8(1), 4-13.

Hernon, P. (2002) Editorial: the practice of outcomes assessment. Journal of Academic Librarianship 28(1), 1-2.

Iannuzzi, P. (1999) We are teaching, but are they learning: accountability, productivity, and assessment. Journal of Academic Librarianship 25(4), 304-305.

Knight, L.A. (2002) The role of assessment in library user education. Reference Services Review 30(1), 15-24.

Meulemans, Y.N. (2002) Assessment city: the past, present, and future state of information literacy assessment. College \& Undergraduate Libraries 9(2), 61-73.

Rabine, J. \& Cardwell, C.. (2000) Start making sense: practical approaches to outcomes assessment for libraries. Research Strategies 17, 319-355.

Ragains, P. (1997) Evaluation of academic librarian's instructional performance: report of a national survey. Research Strategies 15(3), 159-175.

Roselle, A. (1997) Using the ALA’s Evaluating Library Instruction. Journal of Academic Librarianship 23, $390-397$.

Rossi, P. \& Freeman, H.E. (1993) Evaluation: a systematic approach. Beverly Hills, CA: Sage.

Smith, K.R. (2000) New roles and responsibilities for the university library: advancing student learning through outcomes assessment. Association of Research Libraries. Online. http://www.arl.org/stats/newmeas/outcomes/HEOSmith.html

Stewart, S.L. (1999). Assessment for library instruction: the Cross/Angelo model. Research Strategies 16(3), 165-174.

Thompson, G.B. (2002) Information literacy accreditation mandates: what they mean for faculty and librarians. Library Trends 51(2), 218-241.

Tancheva, K.; Cosgrave, T.; \& Cole, V. (2005, May) Cornell University Library (CUL) Instruction Services Survey: A User Assessment. CUL Technical Reports and Papers. Retrieved February 16, 2006 from http://techreports.library.cornell.edu:8081/Dienst/UI/1.0/Display/cul.lib/2005-4.

Wang, R. (2006) The lasting impact of a library credit course. [Electronic version] Portal 6(1), 79-92. 


\section{FIGURES}

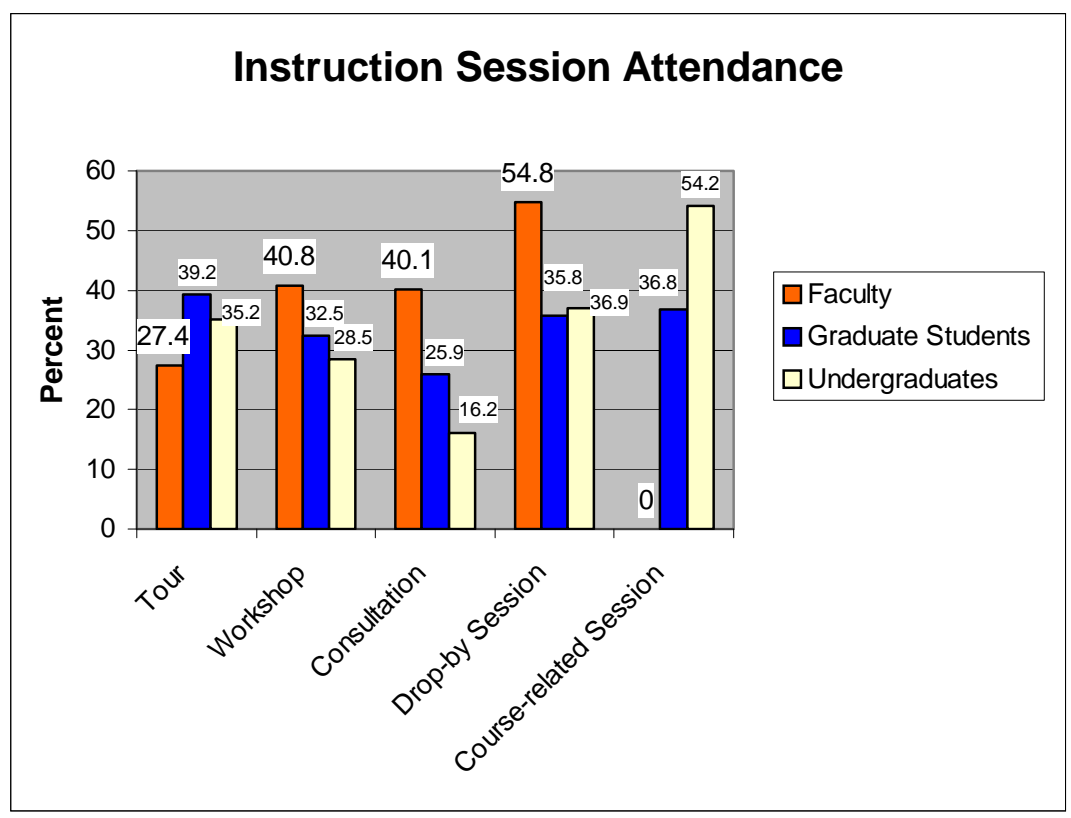

Chart 1: Instruction Session Attendance

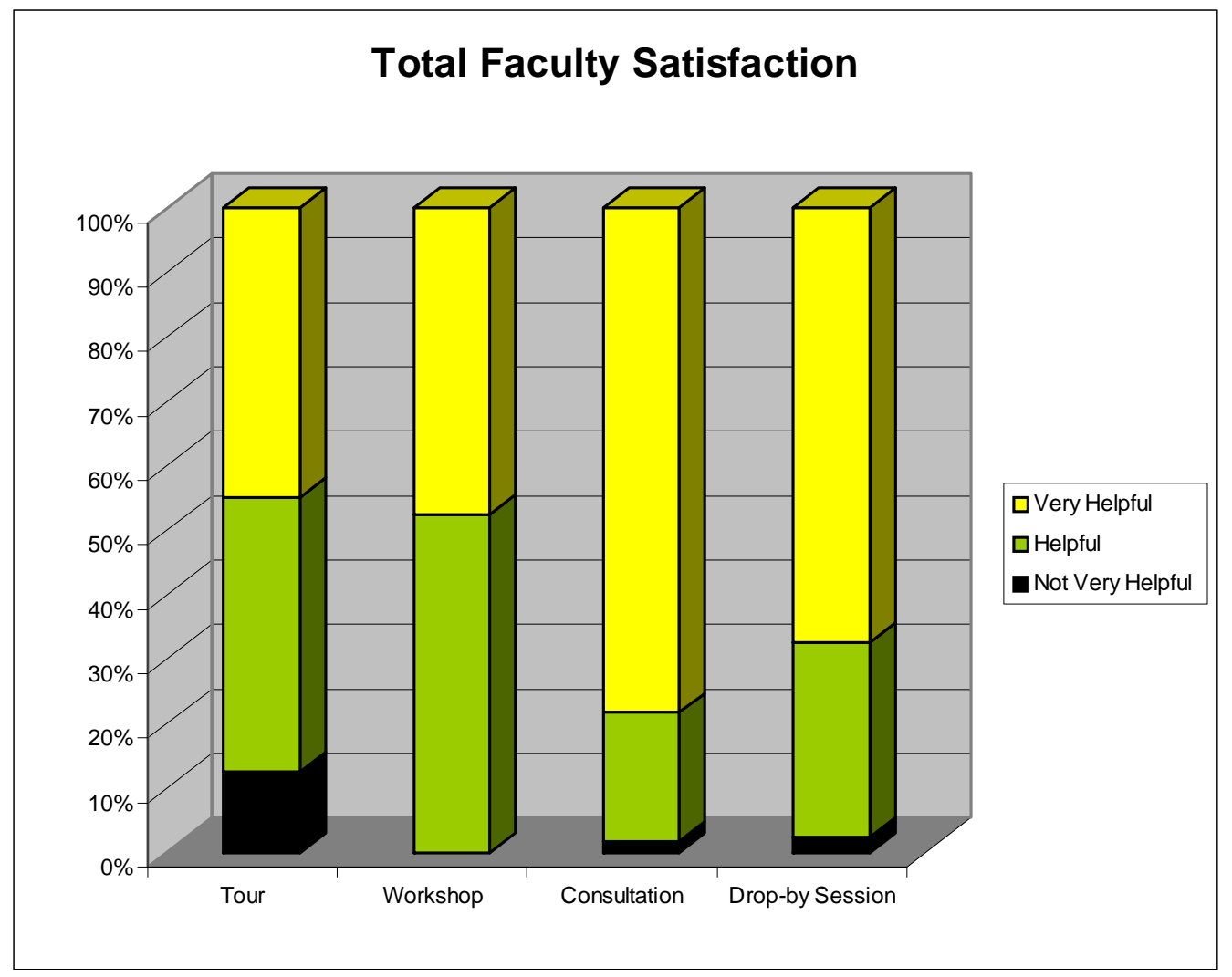

Chart 2: Total Faculty Satisfaction 


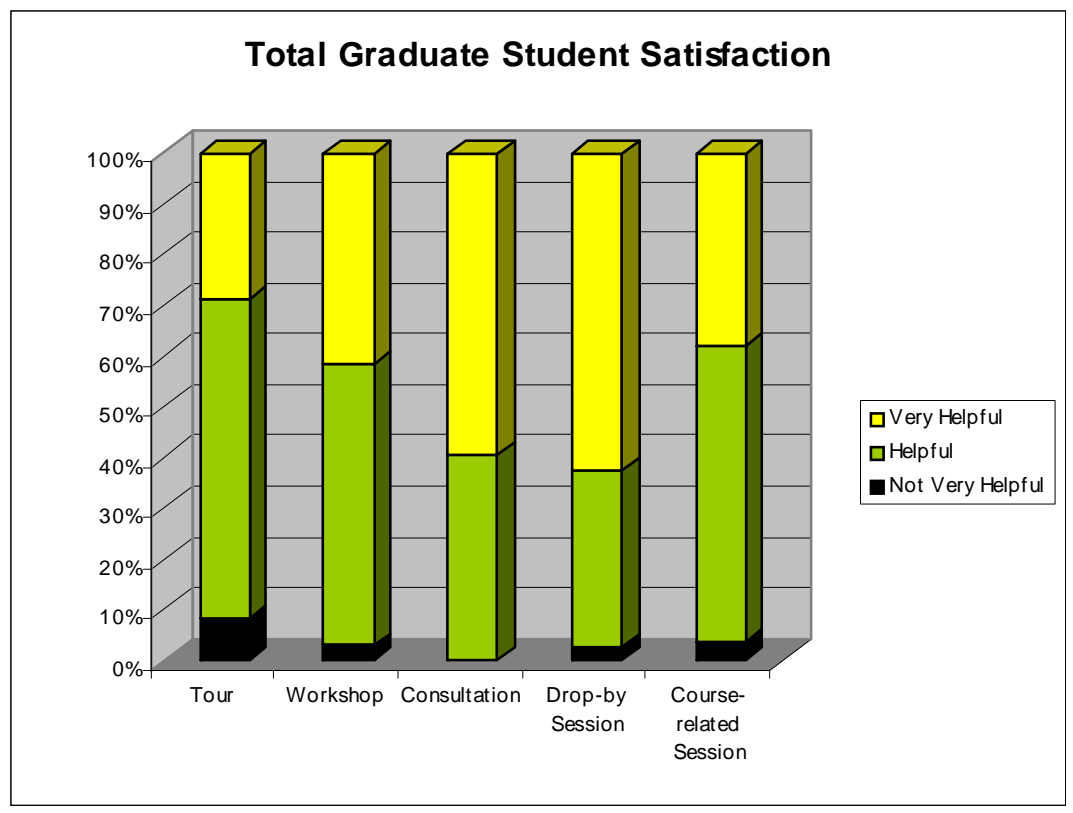

Chart 3: Total Graduate Student Satisfaction

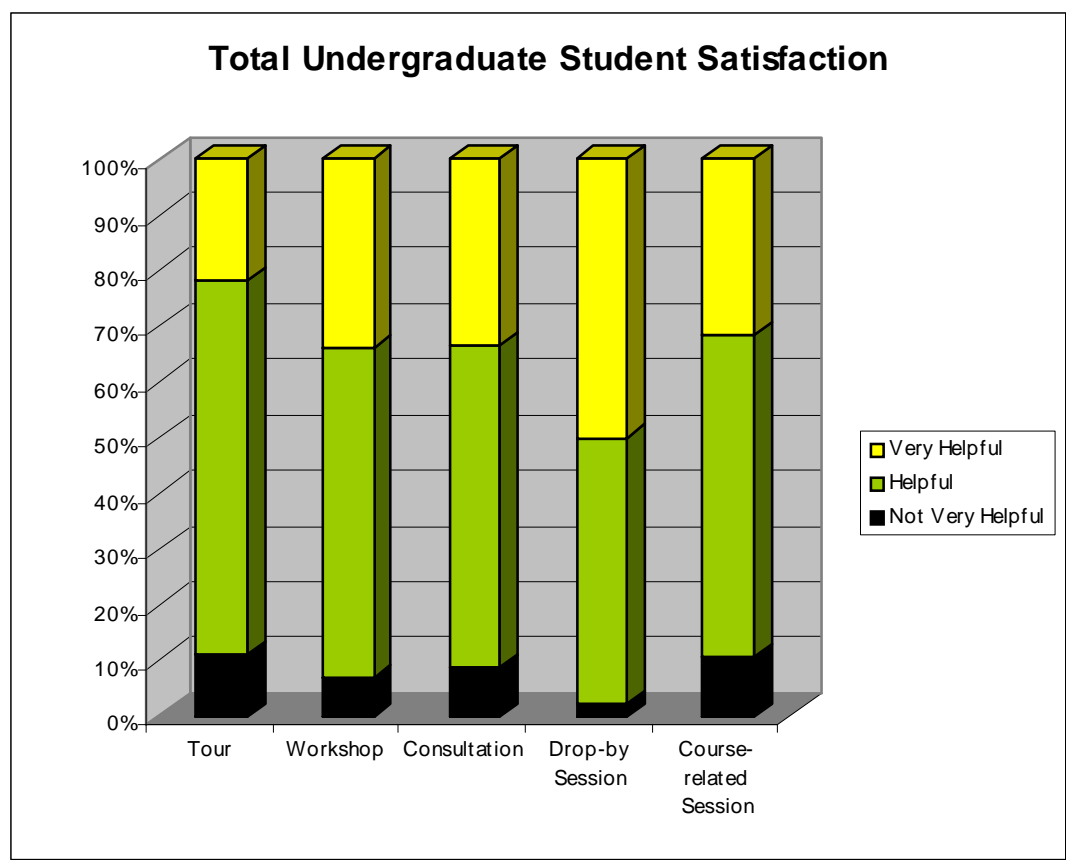

Chart 4: Total Undergraduate Student Satisfaction 


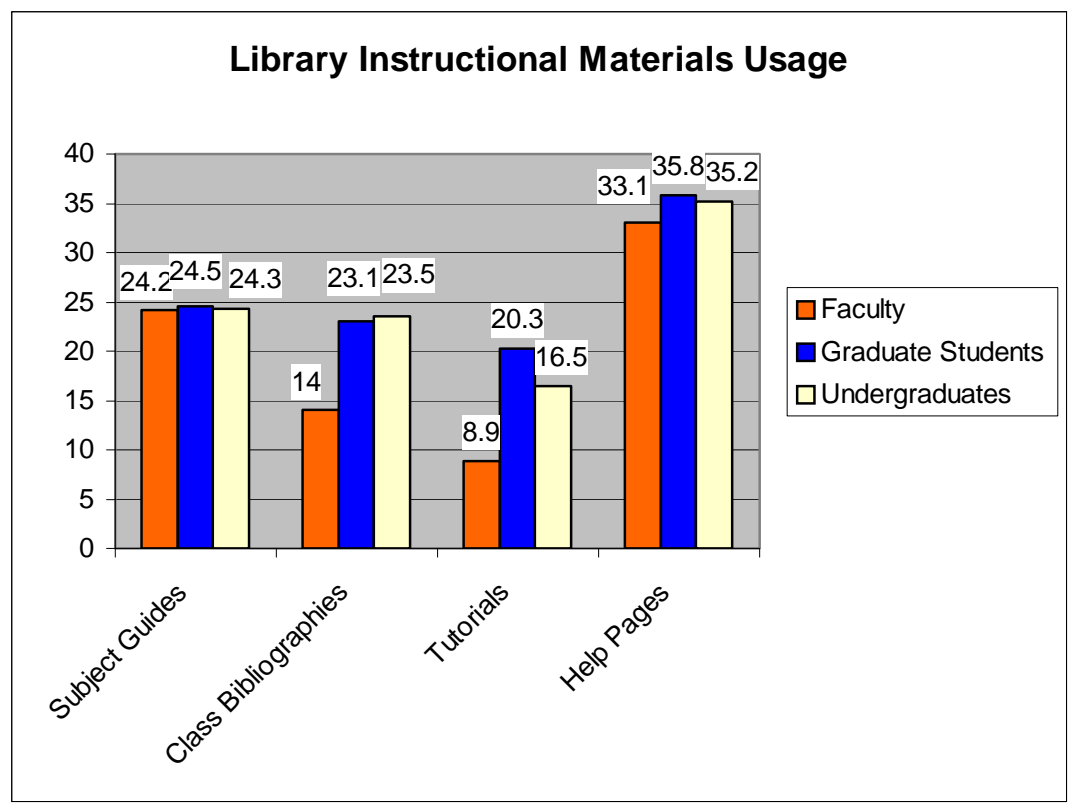

Chart 5: Library Instructional Materials Usage

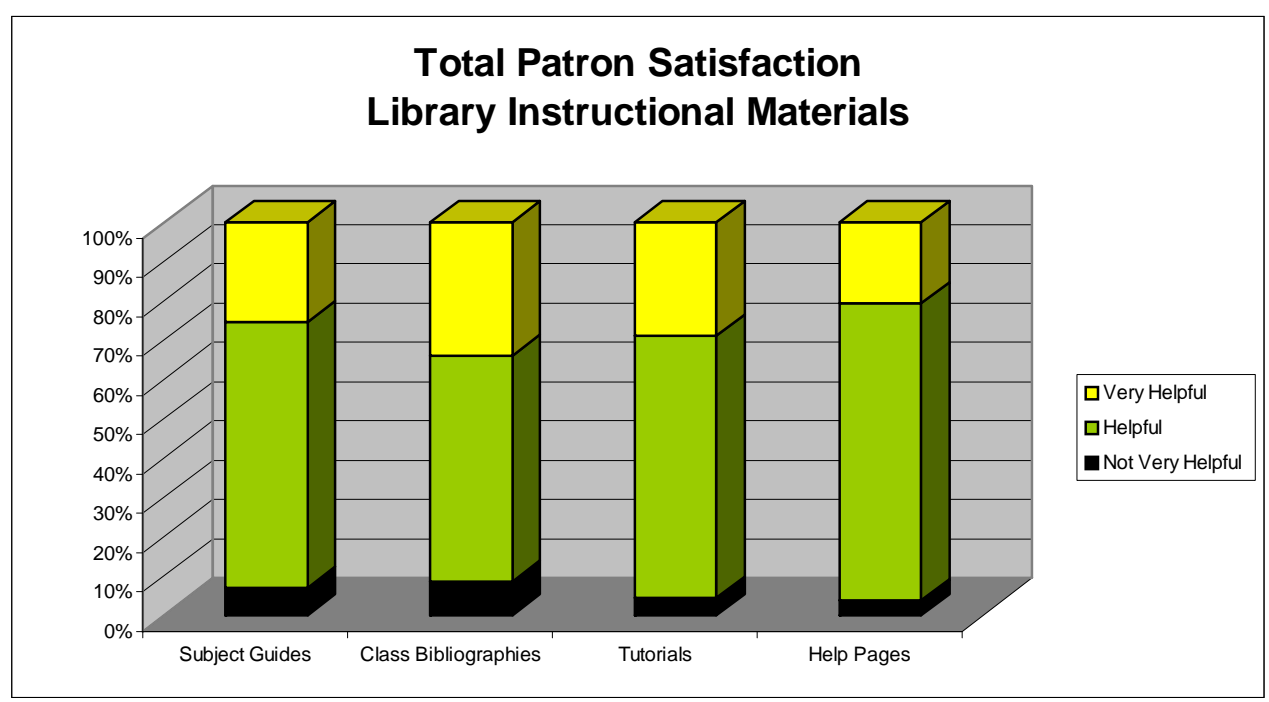

Chart 6: Total Patron Satisfaction: Library Instructional Materials 


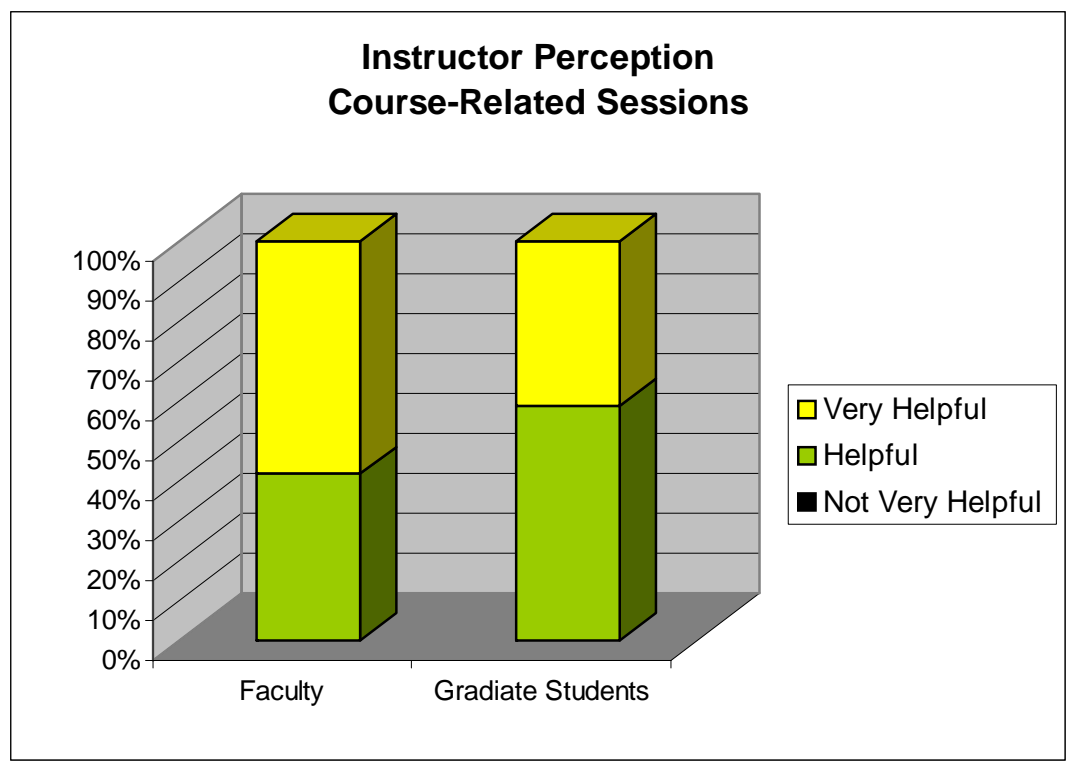

Chart 7: Instructor Perception of the Usefulness of Course-Related Sessions

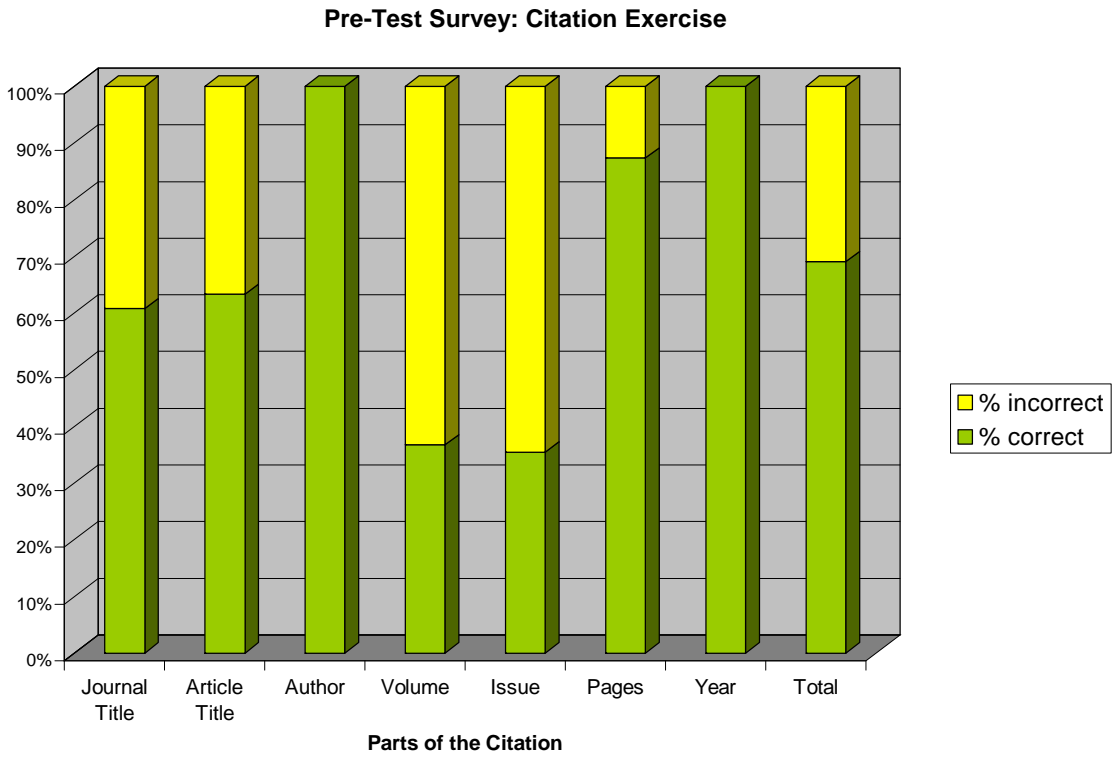

Chart 8: Pre-Test Survey: Citation Exercise 


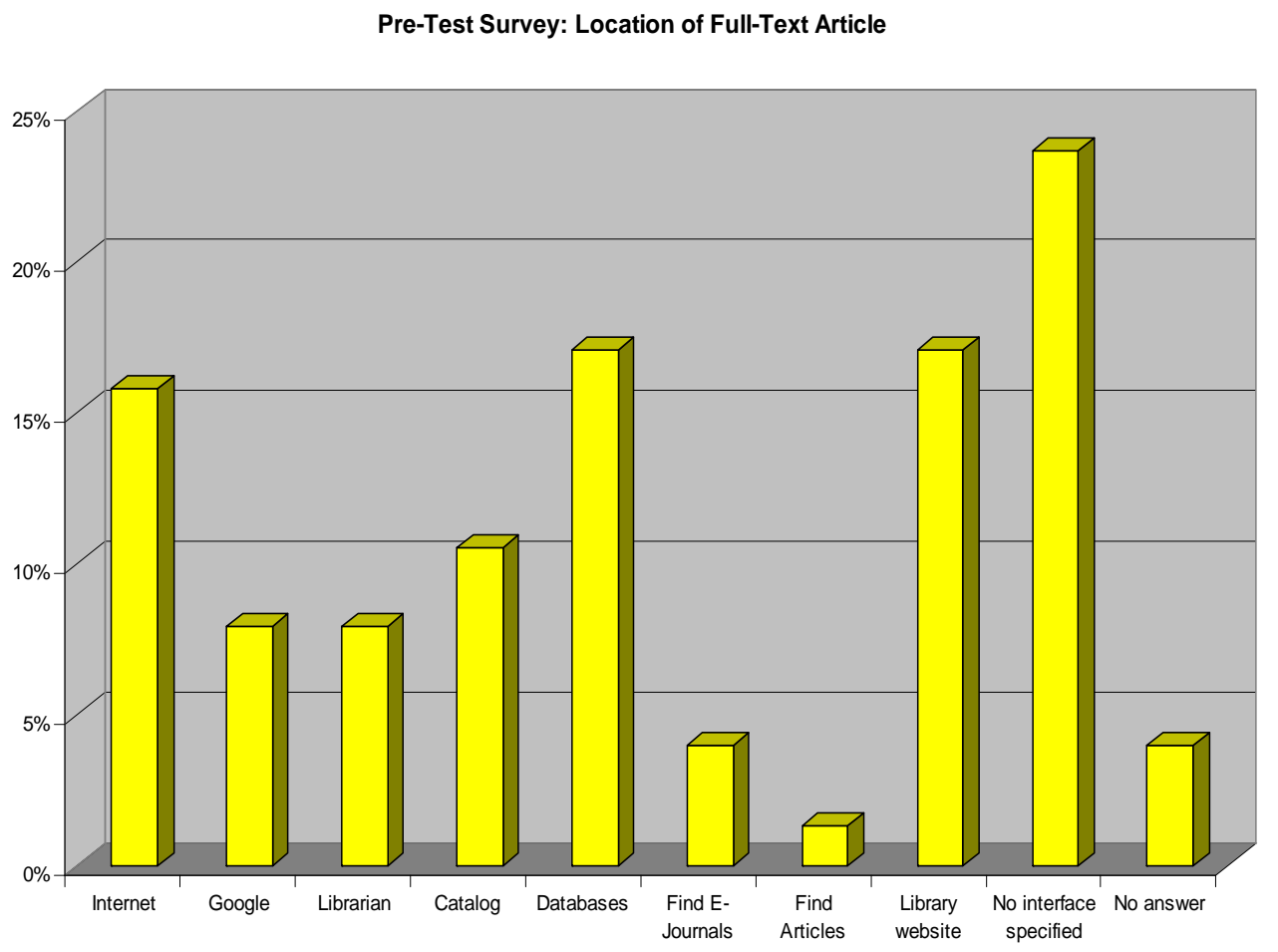

Chart 9: Pre-Test Survey: Location of Full-Text Article

Post-Instruction Tutorial: Citation Exercise

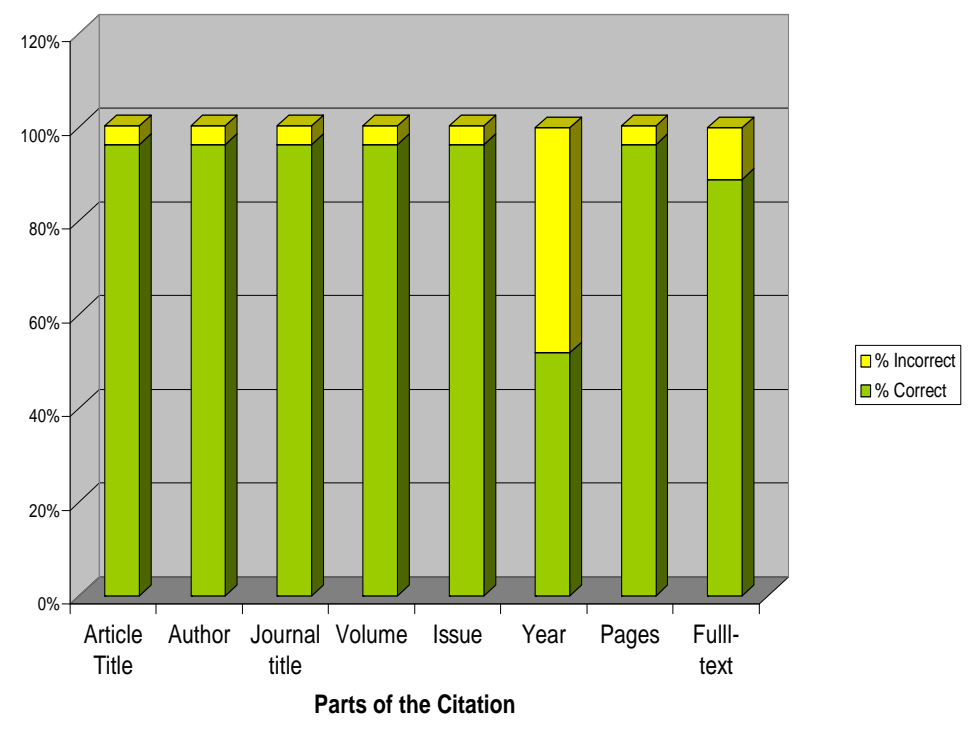

Chart 10: Post-Instruction Tutorial: Citation Exercise 


\section{APPENDIX 1}

Survey for AEM 101 Class

Please complete the following two questions. This should take no more than five minutes and we thank you for your participation.

Identify the parts of the following citation.

Cobe, P. (2005) The Next Wave. Restaurant Business. New York: 104(12) 44-8.

Issue:

Article title:

Author(s):

Volume:

Journal Title:

Pages:

Year:

HOW WOULD YOU FIND THE ARTICLE ABOVE? 


\section{APPENDIX 2}

\section{AEM 101 ASSIGNMENT I: LIBRARY RESEARCH}

This assignment is meant to help you develop your library research skills further and demonstrate that you understand the principles of doing library research at Cornell.

The assignment is due on 9/26/05.

If you have any questions, please contact the Mann Library Reference Desk via e-mail (mannref@cornell.edu) or phone: 255-5406.

\section{Locating journal and news articles through ABI/Inform (Proquest Direct)}

1. Connect to the Library Gateway at http:/library.cornell.edu/ select the Find Databases link under Research Tools, type ABI in the search box, and enter.

2. Click on the title to access the database. Once in the database, click on Databases Selected (under the top navigation bar to the left) and select ABI/Inform Global only ( ${ }^{\text {nd }}$ on the list) unclicking all other files. Click on the Continue button at the top.

3. Your first task is to locate the citation to an article describing a study on the profitability of the discount retail industry and its impact on e-commerce, published in a recent volume of The Journal of Business Strategies.

a/Describe your research strategy:

Type of Search Used (e.g. Basic, Advanced, by Publication):

Search Terms Used (Include all of your search strategies here):

Fields Used With Each Search Term (e.g. Citation and Abstract, Author, Subject, etc.):

Date Range Used, if Any:

Any Limits Applied, if Any:

Write down the citation retrieved:

Article Title: 
Article Author(s):

Journal Title:

Journal Volume, Issue, Year, Inclusive Page Numbers:

Is the article available in full text?

\section{Locating journals through the CUL Catalog.}

Your task is to determine whether CUL carries the volume of the Journal of Business Strategies, in which the article you retrieved was published.

1. Connect to the CUL Catalog at http://catalog.library.cornell.edu/

2. Select a Search Type (Basic, Guided, or Reserve)

3. Search for the Journal

a/What type of search did you use?

b/Which fields did you search?

c/Does CUL carry the journal in print?

d/If yes, which libraries? Include the call numbers of all locations, if applicable.

e/Does Mann Library have the volume of the journal you are looking for?

$\mathrm{f} /$ Is the journal available electronically? Is the article available electronically? If yes, print the first page and submit it as part of this assignment. 


\section{APPENDIX 3}

Mann Library Workshop Survey (Fall 2004)

Dear Workshop Attendee,

Please help us determine the relevance of our instruction program by filling out the brief survey below.

If you have any questions about the instruction program at Mann Library or this survey, please contact Kornelia Tancheva at kt18@cornell.edu.

Thank you for your time.

1) Which workshop did you attend?

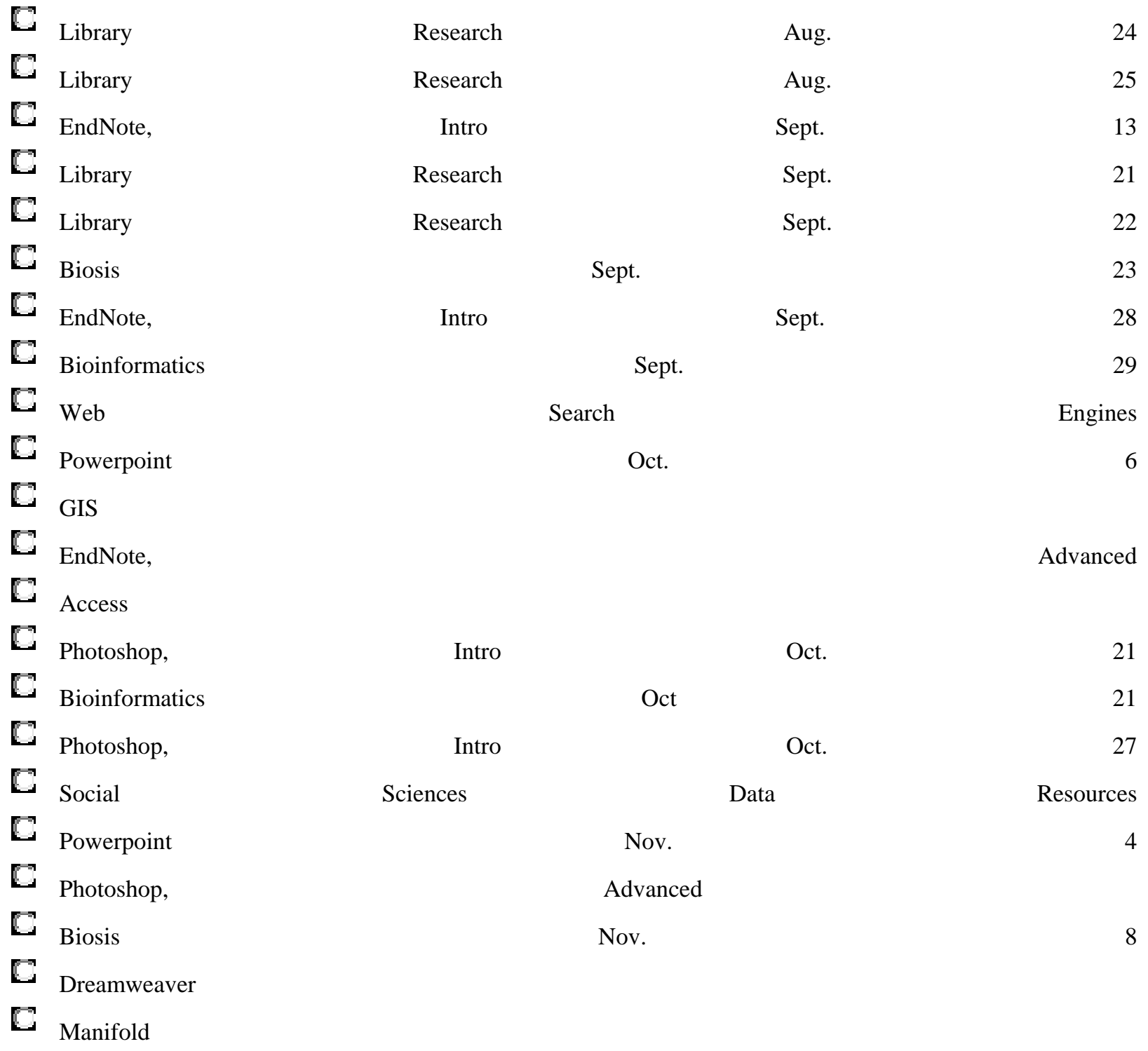

2) Please tell us the most helpful thing(s) that you learned in this class. 


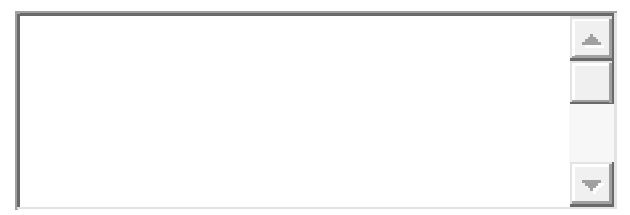

3) Were there things that you wanted to learn but did not? Please exlain.

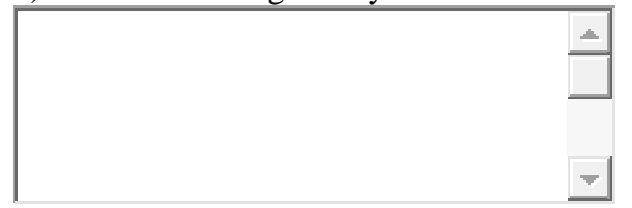

4) Had you taken any library instruction before?

$\boldsymbol{C}$ Yes $\boldsymbol{C}$ No

5) If you answered "yes" to Question \#4, please explain what library instruction you had taken before this session. If you answered "no," proceed to Question \#6.

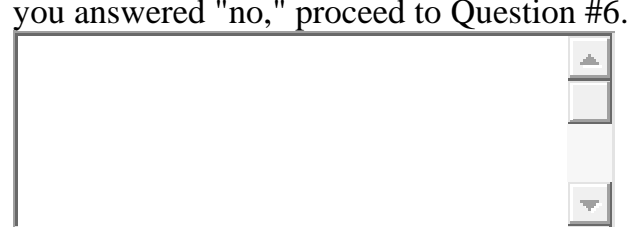

6) Other comments:

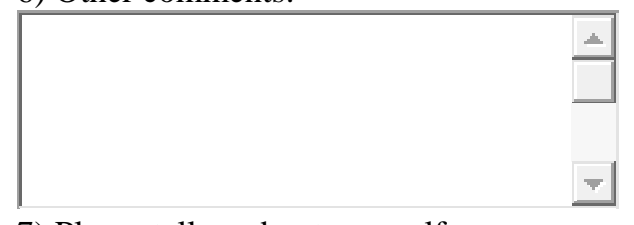

7) Please tell us about yourself:

8) College you are most closely associated with:

-

9) Department:

Thank you 